Portland State University

PDXScholar

\title{
Parallelized Particle Swarm Optimization to Estimate the Heat Transfer Coefficients of Palm Oil, Canola Oil, Conventional, and Accelerated Petroleum Oil Quenchants
}

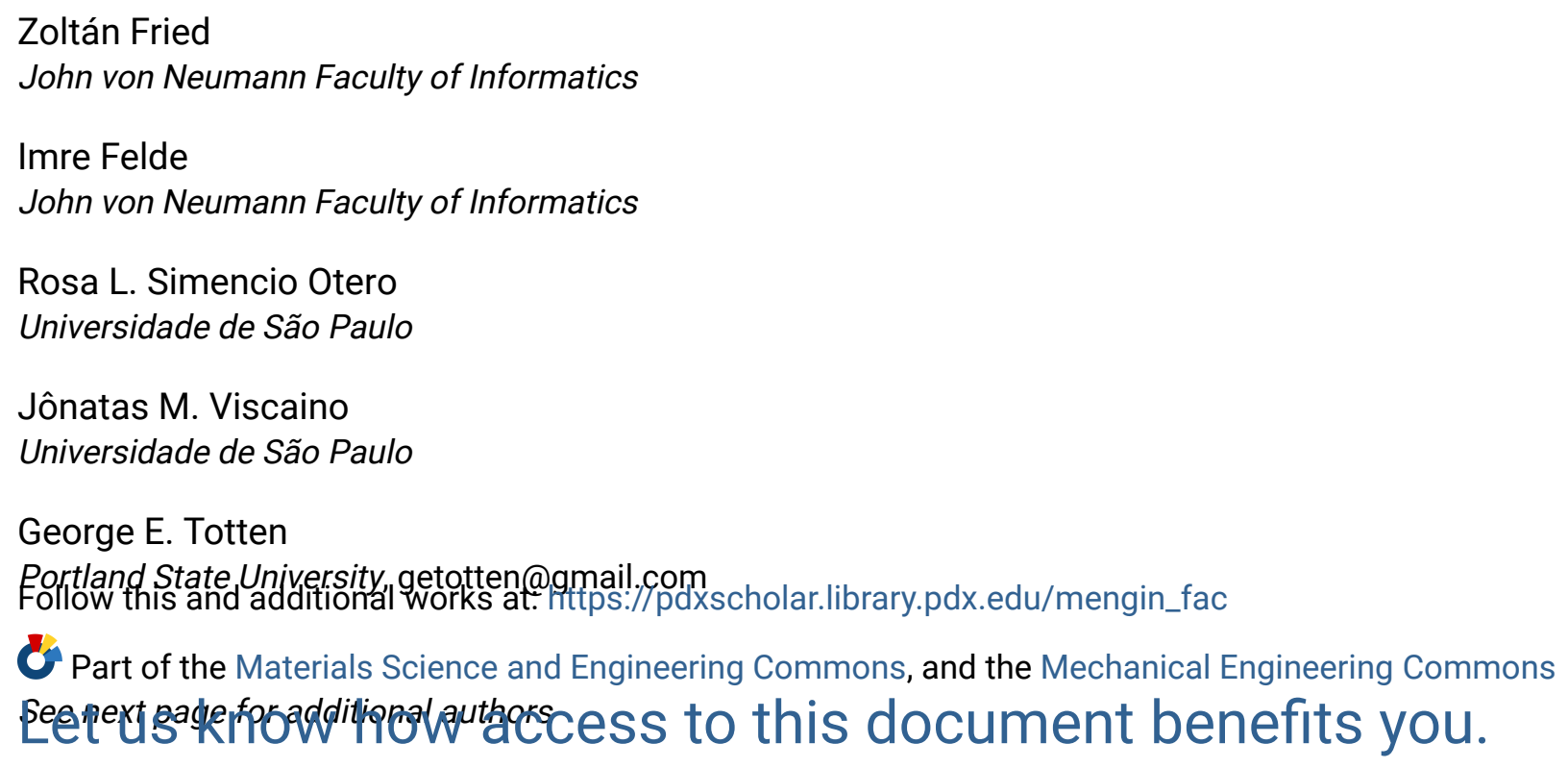

\section{Citation Details}

Canale, L. C., Totten, G. E., Viscaino, J. M., Otero, R. L. S., Fried, Z., \& Felde, I. (2019). Parallelized Particle Swarm Optimization to Estimate the Heat Transfer Coefficients of Palm Oil, Canola Oil, Conventional, and Accelerated Petroleum Oil Quenchants. Materials Performance and Characterization, 8(2).

This Article is brought to you for free and open access. It has been accepted for inclusion in Mechanical and Materials Engineering Faculty Publications and Presentations by an authorized administrator of PDXScholar. Please contact us if we can make this document more accessible: pdxscholar@pdx.edu. 


\section{Authors}

Zoltán Fried, Imre Felde, Rosa L. Simencio Otero, Jônatas M. Viscaino, George E. Totten, and Lauralice Canale 


\section{Materials Performance and Characterization}

Zoltán Fried, Imre Felde, ${ }^{1}$ Rosa L. Simencio Otero, ${ }^{2}$ Jônatas M. Viscaino, ${ }^{3}$ George E. Totten, ${ }^{4}$ and Lauralice C. F. Canale ${ }^{3}$

DOI: 10.1520/MPC20180049

Parallelized Particle Swarm Optimization to Estimate the Heat Transfer Coefficients of Palm Oil, Canola Oil, Conventional, and Accelerated Petroleum Oil Quenchants 
Manuscript received March 14 2018; accepted for publication December 5, 2018; published online January 31, 2019.

1 John von Neumann Faculty of Informatics, Becsi ut 96/B, Budapest 1034, Hungary, (1) https://orcid.org/0000-00034126-2480 (I.F.)

2 Department of Materials Engineering, São Carlos School of Engineering, University of São Paulo, Av. João Dagnone, 110 São Carlos, SP 13563-120, Brazil (Corresponding author), e-mail: rosa.simencio@gmail.com, (1) https://orcid.org/0000-00021974-6406

${ }^{3}$ Department of Materials Engineering, São Carlos School of Engineering, University of São Paulo, Av. João Dagnone, 110 São Carlos, SP 13563-120, Brazil, (1) http://orcid.org/0000-00018865-3396 (J.M.V.), (1) https:// orcid.org/0000-0002-0193-1902 (L.C.F.C.)

${ }^{4}$ Department of Mechanical and Materials Engineering, Portland State University, Portland, PO Box 751, Portland, OR 97207-0751, USA, (D) https://orcid.org/00000002-7313-1437
Zoltán Fried, ${ }^{1}$ Imre Felde, ${ }^{1}$ Rosa L. Simencio Otero, ${ }^{2}$ Jônatas M. Viscaino, ${ }^{3}$ George E. Totten, ${ }^{4}$ and Lauralice C. F. Canale ${ }^{3}$

\section{Parallelized Particle Swarm Optimization to Estimate the Heat Transfer Coefficients of Palm Oil, Canola Oil, Conventional, and Accelerated Petroleum Oil Quenchants}

\section{Reference}

Fried, Z., Felde, I., Simencio Otero, R. L., Viscaino, J. M., Totten, G. E., and Canale, L. C. F., "Parallelized Particle Swarm Optimization to Estimate the Heat Transfer Coefficients of Palm Oil, Canola Oil, Conventional, and Accelerated Petroleum Oil Quenchants," Materials Performance and Characterization https://doi.org/10.1520/MPC20180049.

ISSN 2379-1365

\section{ABSTRACT}

An inverse solver for the estimation of the temporal-spatial heat transfer coefficients (HTC), without using prior information of the thermal boundary conditions, was used for immersion quenching into palm oil, canola oil, and two commercial petroleum oil quenchants. The particle swarm optimization (PSO) method was used on near-surface temperature-time cooling curve data obtained with the so-called Tensi multithermocouple, and a 12.5 by $45 \mathrm{~mm}$ Inconel 600 probe. The fitness function to be minimized by a PSO approach is defined by the deviation of the measured and calculated cooling curves. The PSO algorithm was parallelized and implemented on a graphics accelerator architecture. This article describes, in detail, the PSO methodology used to compare and differentiate the potential quenching properties attainable with vegetable oils versus those attainable with accelerated and conventional petroleum oil quenchant.

\section{Keywords}

quenchant, heat transfer coefficient, particle swarm optimization, vegetable oil, petroleum oil 


\section{Introduction}

Vegetable oils and animal oils have been used as quenchants for metals for thousands of years; however, historically, very little is known about quenching selection and practice from the period prior to $800 \mathrm{AD}$ to approximately $1500 \mathrm{AD}$ [1]. Eamon described various methods used to quench iron and steel during this time [2]. Although cold water was a common quenchant, it reportedly caused brittle steel problems. Reportedly, these problems could be solved by mixing water and various animal and plant materials to make an "oily" or "pulpy" quenching bath. Examples included quenching scythes in suet, files in linseed oil and goat's blood, quarry hammers in the juice of crushed caterpillars, and the edges of steel cutting tools into a composition containing one part each of radishes, horseradish, earthworms or larvae, and billy goat's blood when the goat is in a "rut"-a quenching recipe reported to originate from the time of Pliny the Younger (ca. 61-112 AD) [2]. It has recently been shown that these anecdotal references would not be effective for steel quenchants [3]. There are many more recent historical references detailing the successful use of vegetable oils and animal oils to harden steels [4]. Tagaya and Tamura provided the first comparative rigorous structure-performance studies of a series of vegetable and animal oils on their relative ability to harden various steels $[5,6]$. However, although Tagaya and Tamura's work was based on cooling curve analysis, they did not specifically examine the use of heat transfer coefficients (HTCs) to characterize quenching performance.

Various works have been reported describing the use of HTCs to characterize the relative ability of a quenching medium to harden steel. Examples include the works of Russell [7] and Rose [8]. Rose reported that although cooling rate curves versus temperature completely and accurately describe the cooling capacity of quenchants, measured cooling rates also depend on the size, shape, and thermal properties of the steel. To quantify the cooling properties of a quenchant that are independent of the testing conditions, Rose proposed deriving the HTC from the cooling rate data obtained from the cooling curve analysis, assuming that the temperature being measured within the probe used to obtain the cooling curves is equivalent to the interfacial temperature at the probe surface/quenchant interface.

Using this simplified calculation for HTC, Rose constructed and quantified the cooling capacities of various quenchants obtained from $\mathrm{HTCs}$ at $500^{\circ} \mathrm{C}$, which was the temperature of the fastest transformation rate for most grades of steel available at that time (about 1940) [8]. However, Rose's methodology, while relatively simple to perform, does not account for the varying HTC occurring on the steel surface throughout the quenching process.

More recently, Otero et al. [9] and Kobasko et al. [10] have reported HTC values for various vegetable oils, which were obtained using a "simplified" computational method $[10,11]$. Although relatively easy to perform, this method does not readily produce vitally important continuous heat transfer profiles for a quenching medium throughout the cooling process. Such data are much more readily obtained by using an inverse method to solve the heat transfer problem, such as the finite element methods (FEM) utilized by many researches, including recent studies involving vegetable oils reported by Kobasko et al. [10], de Souza et al. [12], Jagannath and Prabhu [13], and Ramesh and Prabhu [14], among others who have utilized FEM-based approaches.

For much of the more recently reported work, a 12.5 -mm-diameter by $60-\mathrm{mm}$-length Inconel 600 cylindrical probe with a Type K thermocouple (TC) inserted to the geometric center was used as the probe for temperature-time data acquisition of the quenching 
process. However, Kobasko and Liščić provided an extensive summary of the relative disadvantages of using such a probe when characterizing the heat transfer properties of various quenching media in the heat-treat shop [15].

Liščić has successfully utilized a larger cylindrical probe with a $50-\mathrm{mm}$ diameter by 200-mm length to effectively characterize the heat transfer properties of quenching media under actual workshop conditions [16]. The TCs are positioned so that only radial heat flow is measured, which is a prerequisite for a 1-D heat transfer calculation. The outer TC (the measured data of which are used as input for heat transfer calculations) is placed $1 \mathrm{~mm}$ below the surface to ensure minimum damping effect of transient surface temperatures. Two additional TCs are placed at the center and midradius on the same plane as the near-surface TC. This probe is an essential component of the heat transfer "Gradient Method" utilized by Liščić to calculate the heat transfer properties of quenching media [16]. Recently, Liščić's gradient methodology was used to calculate heat transfer performance of canola oil and palm oil fluids containing antioxidants in comparison with a locally produced conventional petroleum oil quenchant [17].

Many FEM-based approaches used to determine heat transfer properties involved during the quenching (hardening) process are solving as an ill-posed inverse problem originally proposed by Beck, Blackwell, and St. Clair [18]. An inverse problem means that some of the initial boundary conditions or material properties are not fully specified as determined from the measured temperature profiles at some specific locations. Solutions of the inverse problem are very sensitive to measurement errors, i.e., small errors in the measured data values can produce very large uncertainty in the solution. In general, the exclusivity and stability of an inverse problem solution is not guaranteed.

Inverse problems have been extensively studied because of their applications in various engineering disciplines. Most of the methods approach the inverse heat conduction problem (IHCP) as an optimization problem, i.e., the problem is defined as the minimization of a cost function or a fitness function measuring the difference between measurements and predictions $[19,20]$. With the improvement of computer capability, a variety of numerical techniques and computational methods have been developed to provide accurate solutions for IHCP in the last decade. Among these methods, stochastic optimization methods have become popular means of solving inverse problems because of their capability of finding the global optimal result without computing the complicated gradient of the objective function.

Genetic algorithms have been successfully used for solving many types of IHCPs $[21,22]$. The quantitative evaluation of different numerical optimization techniques showed that stochastic methods could serve more accurate results for IHCP than gradient approaches in recovering complex thermal boundary conditions [23]. The particle swarm optimization (PSO) algorithm became popular in recent years because of its ability to maintain a good balance between convergence and diversity. Additionally, it has been shown that PSO can reduce the instability problems of the classical methods for solving the IHCPs [24-26].

In this work, a PSO optimization methodology will be used to facilitate the calculation of HTCs for two vegetable oils (palm oil and canola) for subsequent comparison with values obtained under the same quenching conditions for a fast and slow petroleum quenching oils. Included in this discussion will be a numerical overview of PSO compared with more conventional numerical methods used to determine HTCs under laboratory quenching conditions. This discussion will provide the algorithms required to apply this 
methodology to other quenching problems. Finally, a comparison of the HTCs obtained by PSO versus those obtained by a conventional FEM method is included.

\section{Experimental}

The two vegetable oils used for this work, canola oil and palm oil, were purchased at the local market in São Carlos, Brazil, and were used in as-purchased condition, i.e., without the addition of antioxidants. The quenching performance of these oils was compared to two commercially available quenching oils: Houghto-Quench 100 (a conventional "slow" oil) and Houghto-Quench KM (an accelerated "fast" oil).

Kinematic viscosity was measured at $40^{\circ} \mathrm{C}$ and $100^{\circ} \mathrm{C}$ according to ASTM D44517a, Standard Test Method for Kinematic Viscosity of Transparent and Opaque Liquids (and Calculation of Dynamic Viscosity) [27]. The viscosity index was determined from the kinematic viscosities at $40^{\circ} \mathrm{C}$ and $100^{\circ} \mathrm{C}$ according to ASTM D2270-04, Standard Practice for Calculating Viscosity Index From Kinematic Viscosity at 40 and $100^{\circ} \mathrm{C}$ [28].

Cooling curves were obtained under unagitated conditions according ASTM D620001, Standard Test Method for Determination of Cooling Characteristics of Quench Oils by Cooling Curve Analysis, at bath temperatures of $60^{\circ} \mathrm{C}$ [29]. However, instead of the standard $12.5-\mathrm{mm}$ diameter by $60-\mathrm{mm}$ length cylindrical Inconel 600 assembly specified in ASTM D6200-01, a multiple-TC probe assembly (Tensi probe), as shown in Fig. 1, was used. After heating the Tensi probe in a furnace to $850^{\circ} \mathrm{C}\left(1,562^{\circ} \mathrm{F}\right)$, it was then manually and rapidly immersed into $2,000 \mathrm{~mL}$ of the oil to be tested, which was contained in a tallform stainless steel beaker. The probe cooling temperature and cooling times were

FIG. 1

Schematic illustration of the

Tensi probe assembly used for this work.

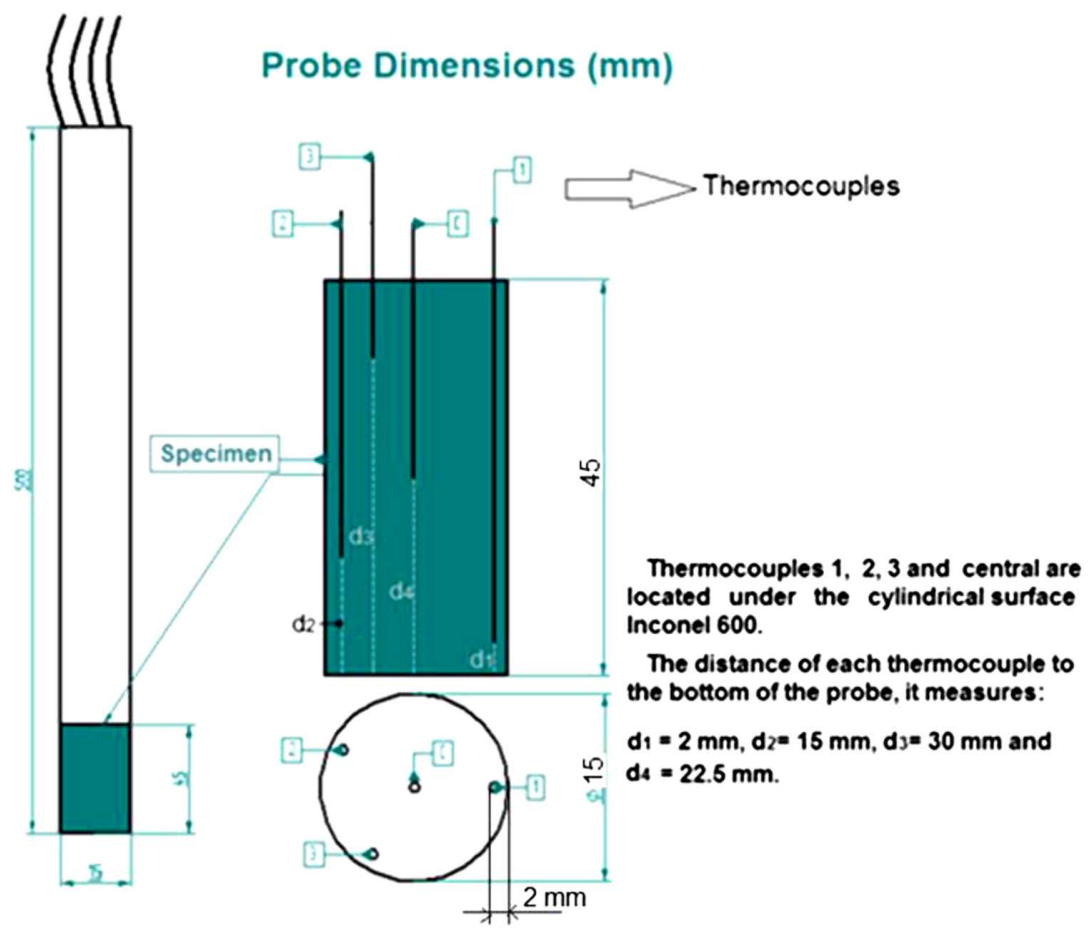


obtained at a data acquisition rate of $8 \mathrm{~Hz}$ and saved on disk storage and used to establish a cooling temperature versus time curve. (This temperature-time data file was also used for the MATLAB computational work described in the following section.)

From the cooling curves obtained for the center TC, the following critical parameters were obtained:

1. Film boiling to nucleate boiling transition time $(\mathrm{s})\left(t_{\mathrm{A}-\mathrm{B}}\right)$

2. Temperature of film boiling to nucleate boiling transition $\left({ }^{\circ} \mathrm{C}\right)\left(T_{\mathrm{A}-\mathrm{B}}\right)$

3. Film boiling to nucleate boiling transition cooling rate $\left({ }^{\circ} \mathrm{C} / \mathrm{s}\right)\left(C R_{D H \min }\right)$

4. Cooling rate at $700^{\circ} \mathrm{C}\left({ }^{\circ} \mathrm{C} / \mathrm{s}\right)\left(C R_{700}\right)$

5. Maximum cooling rate $\left({ }^{\circ} \mathrm{C} / \mathrm{s}\right)\left(C R_{\max }\right)$

6. Temperature of the maximum cooling rate $\left({ }^{\circ} \mathrm{C}\right)\left(T_{C R \max }\right)$

7. Cooling rate at $300^{\circ} \mathrm{C}\left({ }^{\circ} \mathrm{C} / \mathrm{s}\right)\left(C R_{300}\right)$

8. Time to cool to $300^{\circ} \mathrm{C}(\mathrm{s})\left(t_{300}\right)$

9. Cooling rate at $200^{\circ} \mathrm{C}\left({ }^{\circ} \mathrm{C} / \mathrm{s}\right)\left(C R_{200}\right)$

10. Time to cool to $200^{\circ} \mathrm{C}(\mathrm{s})\left(t_{200}\right)$

\section{Methodology}

The heat transfer phenomena that occurs during immersion quenching is widely studied in numerous research fields [30-32]. A significant number of inverse techniques have been proposed and developed to solve problems of inverse heat transfer. Most of these techniques are accomplished by optimizing a certain objective function. The theoretical techniques for solving inverse heat transfer problems can be generally classified into two groups:

1. The gradient-based method (or deterministic algorithm) and

2. The random search-based method (or stochastic/evolutionary-based optimization algorithm)

Numerous estimation problems have been solved by the gradient-based method because of its high computational efficiency. For example, the conjugate gradient method was employed to solve the inverse heat transfer problems to retrieve the HTCs and temperature distribution during continuous water cooling of a Jominy bar by Masson, Loulou, and Artioukhine [33]. Ren et al. [34] studied the inverse estimation of radiative properties and temperature distribution of media through the Levenberg-Marquardt method, respectively. Good agreements between measured and estimated measurement signals were obtained. However, the process for retrieving the gradient in the above gradient-based optimization techniques is relatively difficult. Also, the retrieval results are strongly dependent on the initially guessed values, and even an unfeasible solution can be obtained if the initial value is unsuitable.

In the recent decades, many swarm intelligence algorithms, including differential evolution [35,36], genetic algorithm [37,38], and PSO [39-41], have been analyzed and applied in various industrial fields. These algorithms can effectively overcome the drawbacks and limitations of the aforementioned conventional gradient-based techniques. Moreover, the intelligent algorithms can deal with many feasible solutions at each iteration, and all the processes are performed in parallel. In a recent article, the PSO algorithm suggested by Clerc [42] was applied to determine the HTCs. This is the methodology used for this work and is described in the following section. 


\section{PREDICTION OF HTCS}

The developed IHCP approach is based on temperature signals acquired during the process to be analyzed. The temperature is given by measurements at $p$ points in the solid region, located at $r_{k},(k=1 \ldots p)$ positions inside the workpiece. On calling $T_{k}{ }^{m}$, the measured temperatures, and $T_{k}^{c}$, the calculated temperature at those points, the solution of the IHCP can be obtained by minimizing the objective function using Eq 1:

$$
S=\sum_{k=1}^{p}\left(T_{k}^{m}-T_{k}^{c}\right)^{2}=\min
$$

The specimens temperatures $T_{k}^{c}$ are obtained by numerical simulation using the following assumptions. A 2-D axis-symmetric heat conduction model is considered to predict the temperature field in a cylindrical workpiece (the radius and length of the cylinder is noted by $R$ and $Z$, according to Fig. 2). The $\operatorname{HTC}(z, t)$ function is considered on all the surfaces of the cylinder as functions of time and the longitudinal local coordinate. The thermal conductivity, density, and heat capacity are considered to be temperaturedependent properties. The temperature field is estimated by solving the Fourier equation of heat transfer, Eq 2:

$$
\frac{\partial}{\partial r}\left(k(T) \frac{\partial T}{\partial r}\right)+\frac{k(T)}{r} \frac{\partial T}{\partial r}+\frac{\partial}{\partial z}\left(k(T) \frac{\partial T}{\partial z}\right)+q_{v}=\rho(T) C_{p}(T) \frac{\partial T}{\partial t}
$$

with the initial and the boundary conditions

$$
\begin{gathered}
T(r, z, t=0)=T_{0} \\
\left.k \frac{\partial T}{\partial z}\right|_{\substack{0 \leq z \leq z \\
r=R}}=H T C(z, t)\left[T_{q}-T(r=R, z, t)\right] \\
\left.k \frac{\partial T}{\partial r}\right|_{\substack{z=0 \\
0 \leq \leq \leq R}}==H T C(z=0, t)\left[T_{q}-T(r, z=0, t)\right] \\
\left.k \frac{\partial T}{\partial r}\right|_{\substack{z=Z \\
0 \leq r \leq R}}=H T C(z=Z, t)\left[T_{q}-T(r, z=Z, t)\right]
\end{gathered}
$$

where $r$ and $z$ are the local coordinate, $t$ is the time, $T_{0}$ stands for the initial temperature, $T q$ is the temperature of the cooling medium, and $q_{v}$ is the latent heat. (Because there is no latent heat generation during the experiments, the value of $q_{v}$ is always equal to zero.)

For the prediction of the HTC functions occurring during immersion quenching, the objective function of Eq 1 has been minimized using the PSO algorithm. The basic PSO model consists of a swarm of $M$ particles moving in the search space. Each particle is a potential solution to the global optimum. In other words, each particle stands for a set of input parameters by its position $\left(X_{i}\right)$, which could give the lowest fitness value (the global optimum) in the search space. For an $N$-dimensional search space, the position of the $i$ th particle is represented by $X_{i}=\left(x_{i 1}, x_{i 2}, \ldots, x_{i N}\right)$. For each generation, the new particle position is found by adding a displacement to the current position where the displacement is the particle velocity multiplied by a unitary time step, as shown in Eq 7: 
FIG. 2 Schematic representation of the geometry and the boundary conditions of the workpiece. (a) Cooling time-temperature curve for palm oil at $60^{\circ} \mathrm{C}$, no agitation (using Tensi probe). (b) Cooling time-temperature curve for canola oil at $60^{\circ} \mathrm{C}$, no agitation (using Tensi probe). (c) Cooling time-temperature curve for Houghto-quench $\mathrm{HKM}$ petroleum oil (fast quench oil) at $60^{\circ} \mathrm{C}$, no agitation (using Tensi probe). (d) Cooling time-temperature curve for Houghto-quench $\mathrm{H} 100$ petroleum oil (conventional slow quench oil) at $60^{\circ} \mathrm{C}$, no agitation (using Tensi probe).

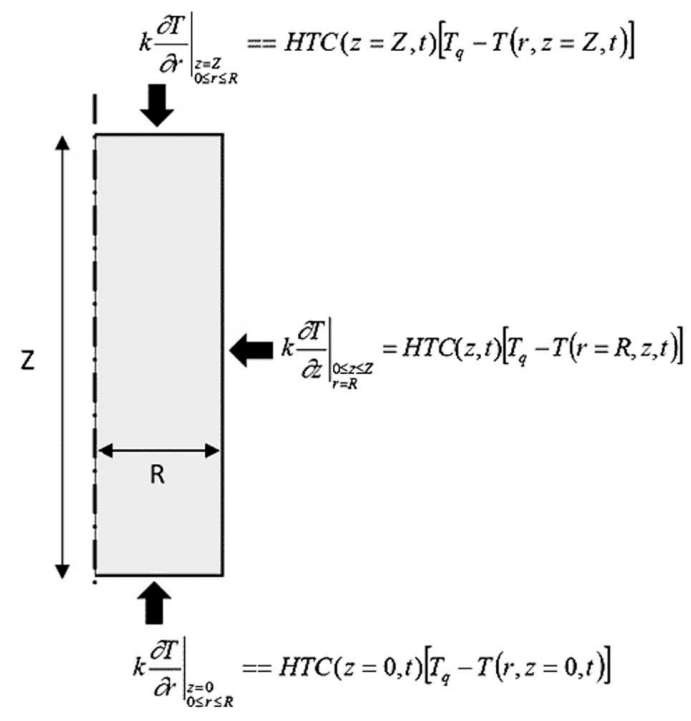

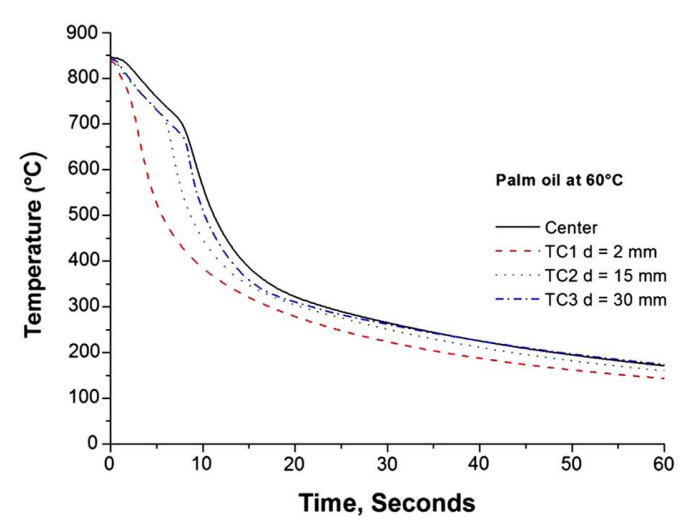

(a)

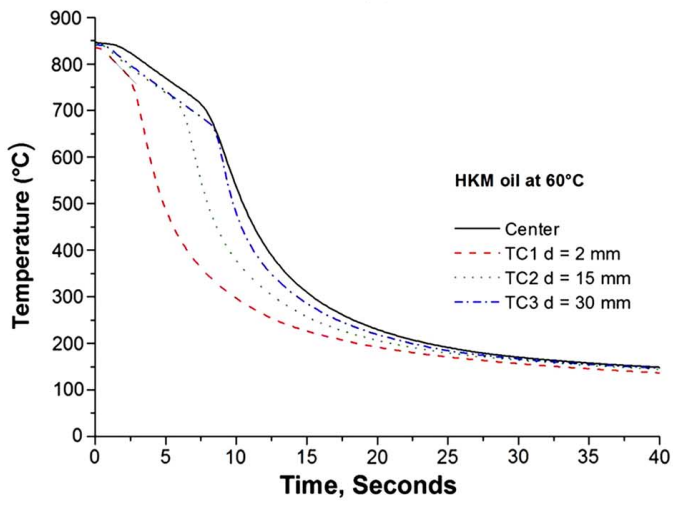

(c)

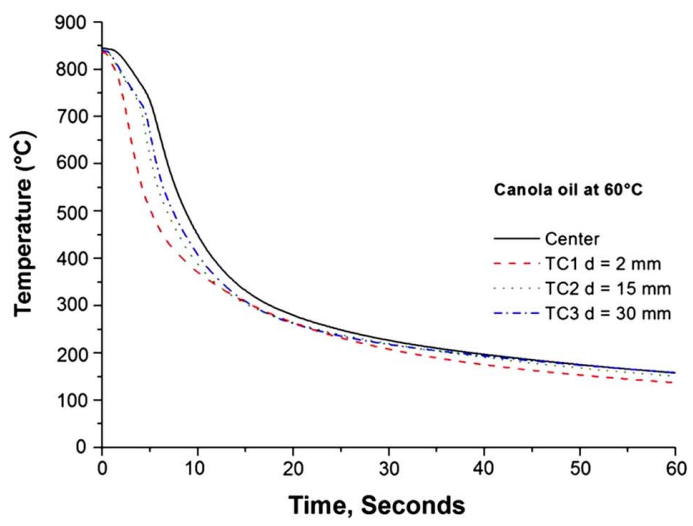

(b)

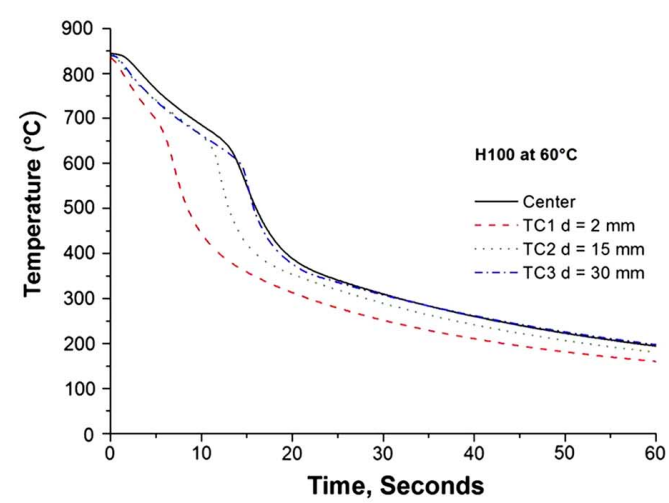

(d) 


$$
X_{i}^{n+1}=X_{i}^{n}+V_{i}^{n+1}
$$

In Eq 7, $X_{i}^{n}$ and $X_{i}^{n+1}$ represent the previous and current positions of particle $i$, respectively, and $V_{i}^{n+1}$ is the current velocity of particle $i$ and is represented as $V_{i}^{n+1}=\left(v_{i 1}\right.$, $\left.v_{i 2}, \ldots, v_{i N}\right)$. The velocity of each particle is also updated for each generation and is given by Srinivasan et al. [30] as follows:

$$
V_{i}^{n+1}=C_{3}\left(V_{i}^{n}+c_{1} r_{1}\left(P_{b e s t, i}-X_{i}^{n}\right)+c_{2} r_{2}\left(G_{b e s t}-X_{i}^{n}\right)\right)
$$

where $V_{i}^{n}$ and $V_{i}^{n+1}$ are the previous and current velocities of the particle $i$, respectively. Each particle maintains a memory of its previous best position, i.e., $P_{b e s t, i}=\left(p_{i 1}, p_{i 2}, \ldots\right.$, $\left.p_{i N}\right)$, the position giving the best fitness function value. The best position among all the particles in the swarm is represented as the global best position, i.e., $G_{b e s t}=\left(p_{g 1}, p_{g 2}, \ldots\right.$, $\left.p_{g N}\right)$. The new velocity in Eq 8 can be seen as the sum of three parts. The constant multiplier $C_{3}$ was set to 0.7298 , and $c_{1}$ and $c_{2}$ were equal to 2.05 [42]. The computational steps of this PSO algorithm are given as follows:

- Step 1: Generate the initial particles in a swarm by randomly generating the position and velocity for each particle.

- Step 2: Evaluate the fitness function of each particle.

- Step 3: Update the $P_{\text {best }, i}$ for each particle if its fitness is smaller than the fitness of its previous best position $\left(P_{\text {best }, i}\right)$.

- Step 4: Update the $G_{b e s t}$ if the fitness function of a particle is smaller than the fitness of the best position of all particles $\left(G_{b e s t}\right)$.

- Step 5: Update each particle according to Eqs 2 and 4.

- Step 6: Repeat the loop until the stopping criteria or a predefined number of generations is reached.

The applied algorithm has been implemented to a graphics accelerator (i.e., general purpose graphic card), which significantly increased the computational efficiency [42].

\section{Results and Discussion}

\section{VISCOSITY RESULTS}

The kinematic viscosity and viscosity index (VI) for the vegetable oils and petroleum oils used in this work are summarized in Table 1. It is important to note that the palm oil and canola oils shown in Table 1 were characterized and used in the as-purchased condition from a local market in São Carlos, Brazil. The viscosity data were compared with values reported in the literature. The kinematic viscosities reported for palm oil by Esteban et al. were 45.34 and $8.21 \mathrm{cSt}$ for $40^{\circ} \mathrm{C}$ and $100^{\circ} \mathrm{C}$, respectively [43]. These values are significantly greater than the values shown in Table 1. The reasons for this discrepancy were not determined as part of this work, although vegetable seed oil properties are composition dependent. Unfortunately, these values are not typically reported.

The literature values for kinematic viscosities of canola oil at $40^{\circ} \mathrm{C}$ and $100^{\circ} \mathrm{C}$ were extrapolated from a table of viscosities as a function of temperature to be $36.89^{\circ} \mathrm{C}$ and $8.56^{\circ}$ $\mathrm{C}$, respectively [44]. These values do compare quite well with the temperatures reported in Table 1. 
TABLE 1

Kinematic viscosity, and viscosity index (VI) determined for palm oil and canola oil and commercial fast and conventional speed petroleum oil based quenchants.

\begin{tabular}{|c|c|c|c|c|}
\hline Viscosity & Palm Oil & Canola Oil & HKM Fast Petroleum Oil & H100 Conventional (slow) Petroleum Oil \\
\hline $\mathrm{m}^{2} / \mathrm{s} \times 10^{-6}\left(@ 40^{\circ} \mathrm{C}\right)$ & 35.06 & 35.33 & 13.72 & 19.52 \\
\hline cSt (@40C) & 35.06 & 35.33 & 13.72 & 19.52 \\
\hline $\mathrm{m}^{2} / \mathrm{s} 10^{-6}\left(@ 100^{\circ} \mathrm{C}\right)$ & 7.89 & 8.30 & 3.27 & 4.23 \\
\hline cSt (@100C) & 7.89 & 8.30 & 3.27 & 4.23 \\
\hline Viscosity Index & 207 & 223 & 106 & 123 \\
\hline
\end{tabular}

The viscosities of both palm oil and canola oil were considerably greater at $40^{\circ} \mathrm{C}$ and $100^{\circ} \mathrm{C}$ than the values shown for either the commercially formulated fast or conventional petroleum oil quenchants. However, the VI values for both petroleum oils were approximately one half of those shown for either vegetable oil. These data indicate that viscositytemperature sensitivities of the two petroleum oil quenchants were substantially greater than the expected viscosity sensitivities for either vegetable oil.

\section{COOLING CURVE ANALYSIS RESULTS}

The cooling time-temperature curves for palm oil, canola oil, Houghto-Quench HKM (a "fast" petroleum quench oil), and Houghto-Quench H100 (a "conventional" petroleum quench oil) for all four positions of the Tensi probe shown in Fig. 1 are provided in Fig. 2a-d, respectively, and the corresponding cooling rate curves for these oils are shown in Fig. 3a-d, respectively. All cooling curves were obtained at $60^{\circ} \mathrm{C}$ in an unagitated condition according to ASTM D6200 [29]. The standard cooling parameters for the center TC location are summarized in Table 2.

Comparing the cooling curves shown in Figs. 2 and 3-for palm oil versus canola oil-it is evident that palm oil exhibited an apparent but relatively short film boiling region, whereas if film boiling actually occurred in canola oil, it was of comparatively shorter duration. This behavior suggests the presence of an as-yet-unidentified more volatile component in the palm oil. The surface cooling curve closest to the bottom end (TC1) of the Tensi probe for both palm oil and canola oil exhibited the fastest cooling as would be expected because of the well-known end-cooling effect. However, the other surface cooling curves were relatively similar to each other, which is consistent with very similar and relatively uniform heat transfer behavior compared with what would be expected for a vaporizable quenchant, such as a fast or slow petroleum quench oil.

The cooling time-temperature curves for Houghto-Quench HKM and Houghtoquench H100 are shown in Fig. $2 \mathrm{c}$ and d, and the cooling rate curves are shown in Fig. $3 c$ and d, respectively. Both petroleum oil quenchants, as expected, exhibited a pronounced film boiling region, with the faster Houghto-quench HKM showing a somewhat shorter duration. Interestingly, all three surface cooling curves are clearly distinguishable and different for both petroleum oil quenchants, which illustrates a moving wetting front, in this case, from bottom upward along the Tensi probe surface. This is a normal and expected behavior for vaporizable quenchants. However, when contrasted with palm oil and canola oil, the data suggest much more uniform surface cooling for both vegetable oils.

The probe centerline cooling parameters summarized in Table 2 illustrate that the two vegetable oils, palm oil and canola oil, cool faster than either petroleum oil quenchant 
FIG. 3 (a) Cooling rate curve for palm oil at $60^{\circ} \mathrm{C}$, no agitation (using Tensi probe). (b) Cooling rate curve for canola oil at $60^{\circ} \mathrm{C}$, no agitation (using Tensi probe). (c) Cooling rate curve for Houghto-quench HKM petroleum oil (fast quench oil) at $60^{\circ} \mathrm{C}$, no agitation (using Tensi probe). (d) Cooling rate curve for Houghto-quench $\mathrm{H} 100$ petroleum oil (conventional quench oil) at $60^{\circ} \mathrm{C}$, no agitation (using Tensi probe).

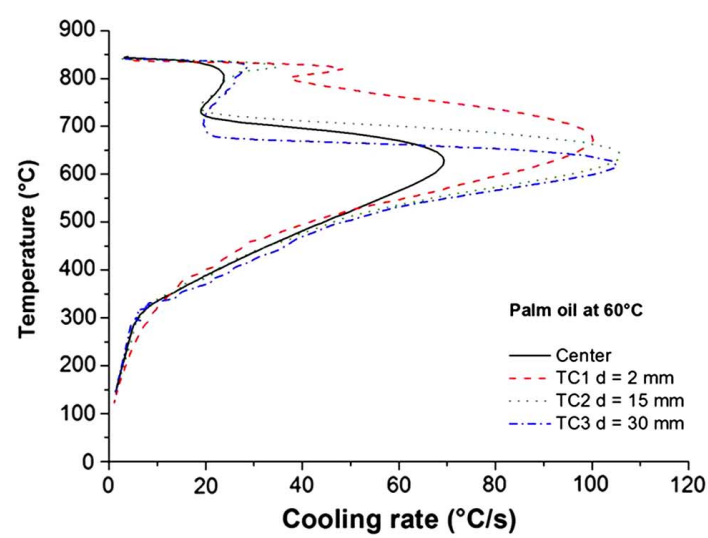

(a)

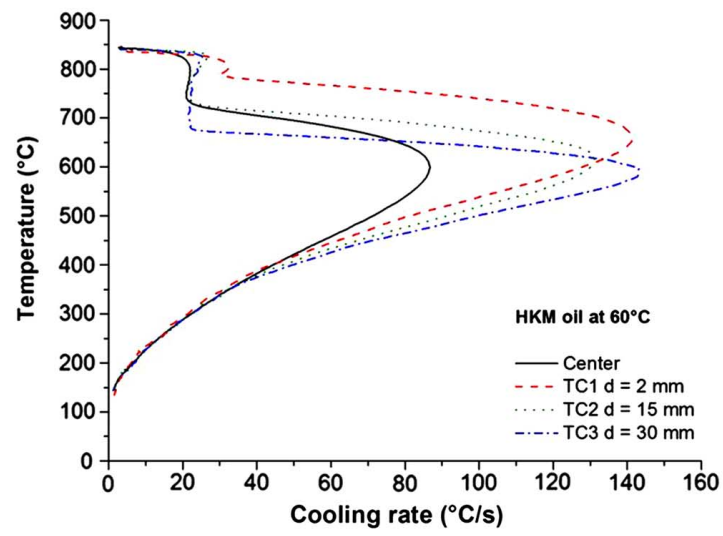

(c)

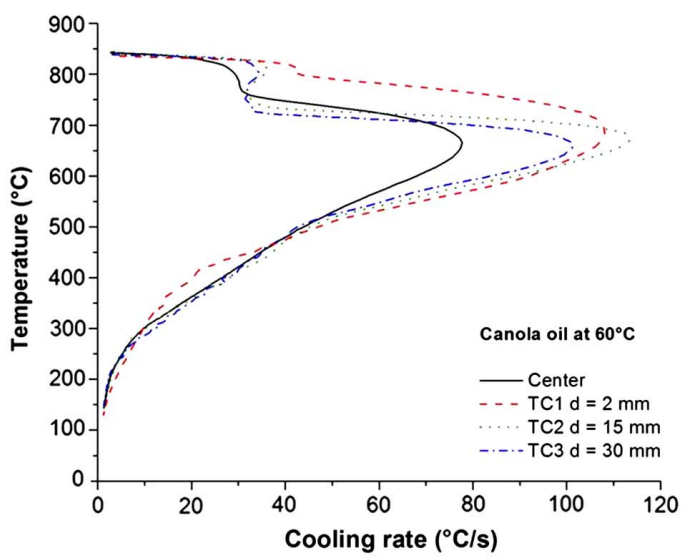

(b)

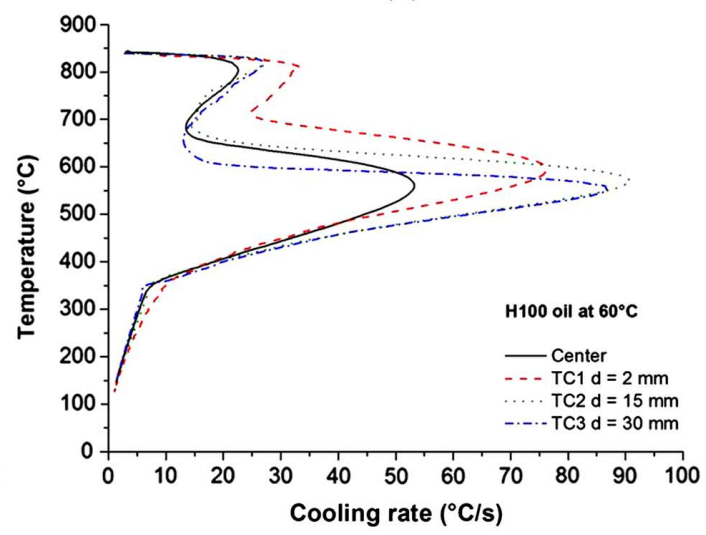

(d)

TABLE 2

Cooling parameters obtained in the geometric center based on ASTM D6200 at a $60^{\circ} \mathrm{C}$ bath temperature and with no agitation.

\begin{tabular}{|c|c|c|c|c|}
\hline $\begin{array}{l}\text { Cooling Curve Parameters Obtained } \\
\text { At } 60^{\circ} \mathrm{C} \text { Bath Temperature }\end{array}$ & Palm Oil & Canola Oil & $\begin{array}{c}\text { HKM Fast } \\
\text { Petroleum Oil }\end{array}$ & $\begin{array}{l}\text { H100 Conventional (Slow) } \\
\text { Petroleum Oil }\end{array}$ \\
\hline$t_{A-B}(\mathrm{~s})$ & 6.6 & 3.8 & 6.4 & 10.7 \\
\hline$T_{A-B}\left({ }^{\circ} \mathrm{C}\right)$ & 729 & 778 & 737 & 678 \\
\hline$C R_{D H \min }\left({ }^{\circ} \mathrm{C} / \mathrm{s}\right)$ & 18.9 & 30.3 & 21.3 & 13.5 \\
\hline$C R_{\max }\left({ }^{\circ} \mathrm{C} / \mathrm{s}\right)$ & 69.4 & 77.7 & 86.7 & 53.2 \\
\hline$T_{C R \max }\left({ }^{\circ} \mathrm{C}\right)$ & 629 & 665 & 599 & 557 \\
\hline$C_{R 700^{\circ} \mathrm{C}}\left({ }^{\circ} \mathrm{C} / \mathrm{s}\right)$ & 35.7 & 71.9 & 44.8 & 14.0 \\
\hline$C_{R 300^{\circ} \mathrm{C}}\left({ }^{\circ} \mathrm{C} / \mathrm{s}\right)$ & 6.1 & 9.8 & 22.1 & 5.4 \\
\hline$C_{R 200^{\circ} \mathrm{C}}\left({ }^{\circ} \mathrm{C} / \mathrm{s}\right)$ & 2.8 & 2.5 & 6.7 & 2.6 \\
\hline$t_{700^{\circ} \mathrm{C}}(\mathrm{s})$ & 7.8 & 5.5 & 7.8 & 9.0 \\
\hline$t_{300^{\circ} \mathrm{C}}(\mathrm{s})$ & 23.2 & 17.6 & 15.5 & 31.8 \\
\hline$t_{200^{\circ} \mathrm{C}}(\mathrm{s})$ & 48.0 & 38.6 & 23.5 & 57.8 \\
\hline
\end{tabular}


with a comparatively shorter film boiling duration. However, the maximum cooling rate was lower for both vegetable oils, although it occurred at a somewhat higher temperature relative to either petroleum oil; and, as expected, the cooling was much faster for Houghtoquench HKM than Houghto-quench H100.

\section{HTC RESULTS}

Table 3 summarizes the HTC (maximum) variation with each near-surface TC position of the Tensi probe (Fig. 2) as calculated by the particle swarm computational methodology. The coordinates of the 3-D plots (Fig. 4) are HTC, elapsed time upon immersion, and the near-surface TC position of the Tensi probe depicted in Fig. 1. This TC position was selected because it is the position where the maximum HTC was observed for the different oils examined.

Fig. 4a shows that palm oil exhibits a pronounced film boiling behavior as observed for both the cooling time-temperature (Fig. 2a) and cooling rate (Fig. 3a) curves. Maximum heat transfer occurs at progressively longer times, indicating an upward movement of the boiling front with respect to time. The largest magnitude of the maximum heat transfer transition was greatest $\left(3,537 \mathrm{Wm}^{-2} \mathrm{~K}^{-1}\right)$ at the $15-\mathrm{mm}$ surface position of the probe.

Canola oil, on the other hand, shown in Fig. 4b, shows a much shorter duration of film boiling; while the maximum heat transfer did progress in an upward movement along the surface of the probe, the total time for cooling to occur was much shorter than exhibited by the palm oil. It is important to note that as opposed to the behavior observed for palm oil, maximum heat transfer occurred at nearly the same time for the 15- and 30-mm surface TC positions, indicating much more uniform heat transfer. Furthermore, the magnitude of the maximum heat transfer $\left(3,752 \mathrm{Wm}^{-2} \mathrm{~K}^{-1}\right)$ at the $15-\mathrm{mm}$ surface position of the probe is in the same position as where the maximum heat transfer occurred (15-mm TC position) for the palm oil.

The heat transfer behavior of the "fast" petroleum oil quenchant HKM shown in Fig. 4c exhibited similar behavior as that observed for palm oil (Fig. 4a). As expected, since petroleum oils do characteristically exhibit significant film boiling behavior, it is observed, by the film boiling behavior indicated, that the rewetting front traverses in an upward axial motion along the surface of the probe. Maximum magnitude of the HKM

TABLE 3

HTC (maximum) variation with the near-surface TC position of the Tensi probe (Fig. 1) as calculated by the particle swarm computational methodology.

\begin{tabular}{lcccc}
\hline & & \multicolumn{3}{c}{ Max. HTC $\left(\mathrm{Wm}^{-2} \mathrm{~K}^{-1}\right)$} \\
\cline { 3 - 5 } Quenchant & & $\mathrm{z}=2 \mathrm{~mm}$ & $\mathrm{z}=15 \mathrm{~mm}$ & $\mathrm{z}=30 \mathrm{~mm}$ \\
\hline Palm Oil & HTC & 1,832 & 3,537 & 7.26 \\
& Time (s) & 3.38 & 3,752 & 3.59 \\
Canola Oil & HTC & 2,083 & 4.74 & 5.08 \\
& Time (s) & 3.45 & 5,714 & 4,719 \\
Houghto-Quench HKM & HTC & 2,706 & 8.49 & 9.22 \\
& Time (s) & 3.77 & 3,015 & 2,591 \\
Houghto-Quench H100 & HTC & 1,722 & 12.07 & 14.95 \\
\hline
\end{tabular}


FIG. 4 Three-dimensional plots of HTCs for each of the three near-surface TC positions for the Tensi probe (Fig. 1) quenched into Houghto-Quench $\mathrm{H} 100$ conventional petroleum oil quenchant at $60^{\circ} \mathrm{C}$ with no agitation, obtained by the particle swarm computational method.
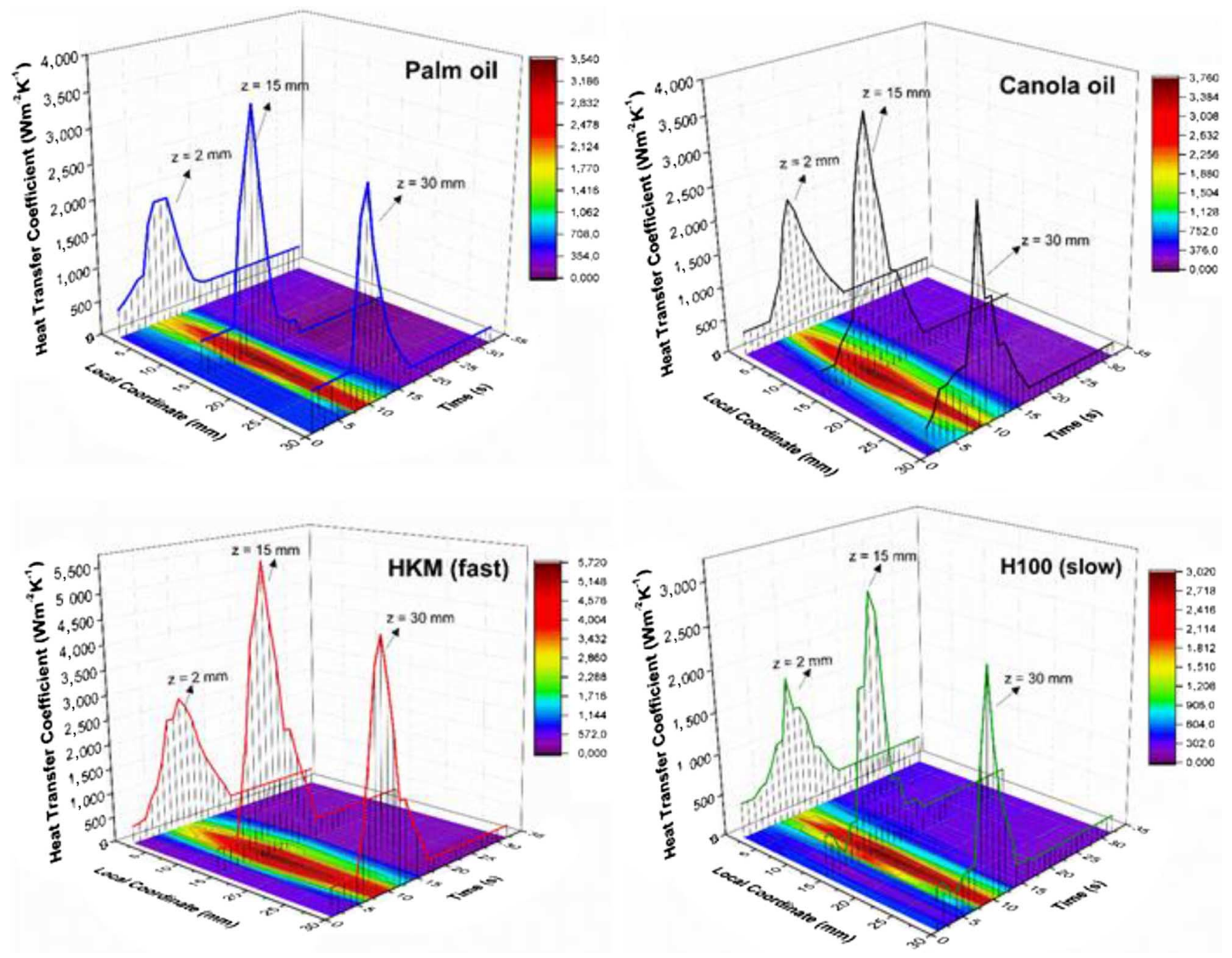

$\left(5,714 \mathrm{Wm}^{-2} \mathrm{~K}^{-1}\right)$, as with palm oil, occurred at the $15-\mathrm{mm}$ surface probe position. This was the largest HTC of any of the oils evaluated in this study.

Heat transfer behavior along the surface of the Tensi probe is shown for the conventional petroleum oil H100 quenchant and is shown in Fig. 4d, which exhibited the longest times for the film boiling transition. As observed for palm oil and the HKM oil, the maximum value of the HTC $\left(3,015 \mathrm{Wm}^{-2} \mathrm{~K}^{-1}\right)$ occurred at the $15-\mathrm{mm}$ surface TC position. Interestingly, the breadth of the maximum HTC peaks was significantly broader for the H100 petroleum oil.

While these data are consistent with the information that is attainable with the cooling time-temperature curves (Fig. 2) and cooling rate curves (Fig. 3), the HTC curves provide a simpler quantitative characterization of quenching behavior.

Fig. 5 provides a comparative illustration of the surface HTC as a function of surface temperature for a 15-mm Inconel 600 cylindrical probe quenched into canola oil, palm oil, a fast petroleum quench oil (HKM), and a conventional petroleum quench oil ( $\mathrm{H} 100)$ at $60^{\circ} \mathrm{C}$ in unagitated conditions. The results show that the fast petroleum quenching oil (HKM) exhibited the highest $H T C_{\max }$ at the highest surface temperature. It is important 
FIG. 5

HTC as a function of surface temperature at the $15-\mathrm{mm}$ surface TC position of the Tensi probe (Fig. 1) quenched into canola oil, palm oil, a fast petroleum quench oil (HKM), and a conventional petroleum quench oil ( $\mathrm{H} 100)$ at $60^{\circ} \mathrm{C}$ in unagitated conditions.

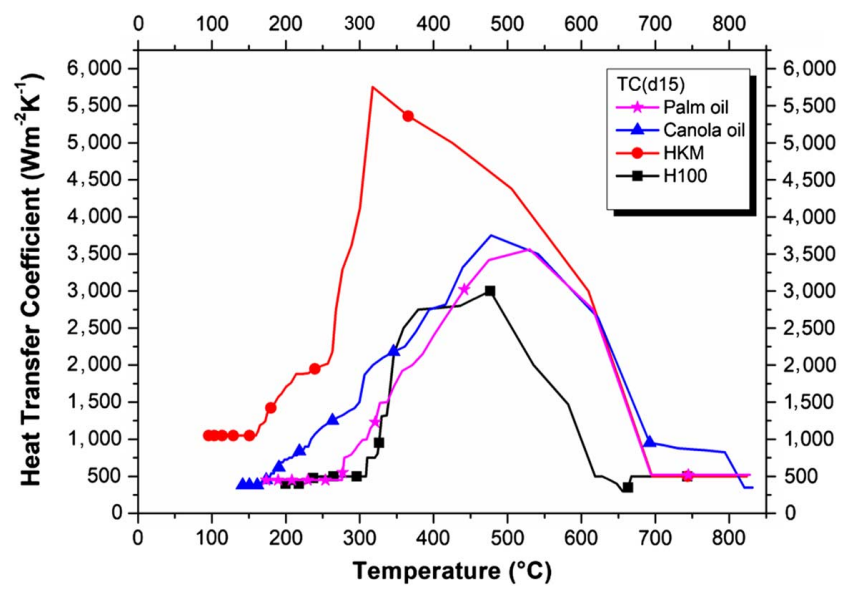

FIG. 6

Comparison of cross-sectional hardness of carbon steel quenched simulated for the 15-mm near-surface TC position of the Tensi probe (Fig. 1) into unagitated canola oil, palm oil, a fast petroleum oil quenchant (HKM), and a conventional petroleum oil quenchant at a bath temperature of $60^{\circ} \mathrm{C}$. to note that although the HKM oil exhibited the highest $H T C_{\max }$, substantial film-boiling behavior occurred as well. The $H T C_{\max }$ of the two vegetable oils, canola oil and palm oil, were similar in magnitude and occurred at similar surface temperatures but less than that exhibited by the HKM petroleum oil. However, the data show a considerably longer film boiling duration for palm oil, which was minimal if it occurred at all. The conventional petroleum oil (H100) exhibited a relatively broad HTC, and its $H T C_{\max }$ was only slightly less than the vegetable oils, although approximately comparable in magnitude and in the same surface temperature region. However, the duration of film boiling behavior was the longest of those oils evaluated.

The predicted hardness of a 15-mm-diameter cylindrical carbon steel test specimen (with the overall dimensions shown in Fig. 1 for the Tensi probe) of the four oils in this study was determined (Fig. 6). The computational methodology used to perform these hardness predictions has already been described [45-47] and will not be detailed further here. The predicted cross-sectional hardness for each oil is shown in Fig. 5.

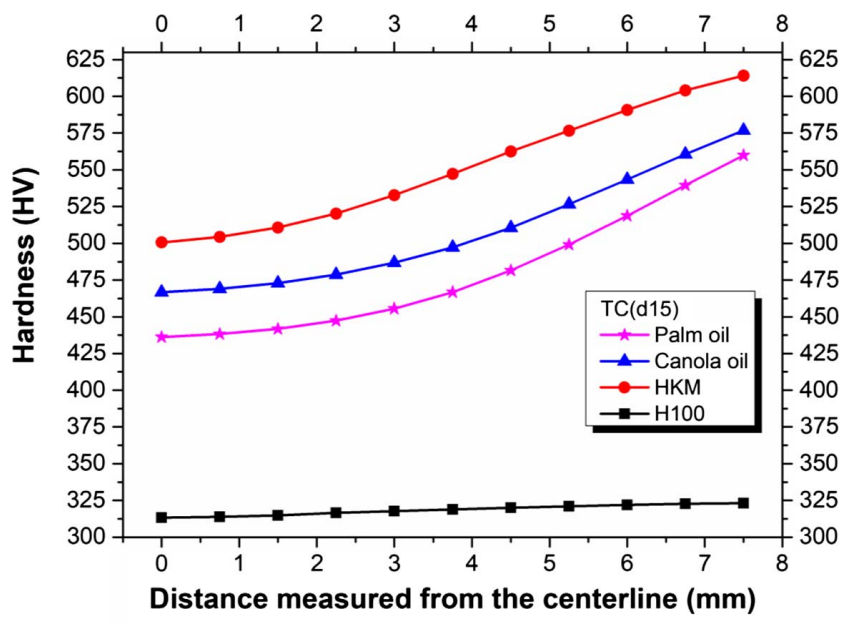


Fig. 5 shows that the fast petroleum oil (HKM) exhibited the highest Vickers crosssectional hardness as expected, which is due to its relatively high $H T C_{\max }$ at the highest surface temperature with a comparatively low duration of film boiling, all of which are favorable conditions for maximizing the as-quenched hardness of a low hardenability carbon steel. Both vegetable oils exhibited lower cross-sectional hardness than the HKM oil. However, of the two vegetable oils, the much shorter film boiling duration of canola oil did provide better hardening conditions than those exhibited for palm oil, although both exhibited comparable $H T C_{\max }$ values that occurred at similar surface temperatures. For the same reason, the $\mathrm{H} 100$ failed to harden the carbon steel because of its unacceptably long film boiling transition time.

\section{Conclusions}

Cooling curve analysis and heat transfer characterization of two vegetable oils, canola oil and palm oil, which were used in their as-purchased condition, were performed. This work was performed using the Tensi probe, an Inconel 15- by $45-\mathrm{mm}$ cylindrical test specimen equipped with three near-surface TCs and one center TC. The cooling curve data showed that although palm oil and canola oil are both vegetable oils, the palm oil exhibited significant film boiling behavior, as became apparent in its cooling time-temperature profile, whereas the canola oil used for this study exhibited little, if any, apparent film boiling behavior. The other cooling curve parameters evaluated were approximately comparable. It is important to note that the rewetting behavior properties suggested by the surface cooling curves indicated that it would be expected that canola oil would exhibit the most uniform quenching behavior of the oils evaluated. However, although this would be expected to result in lower cracking and more uniform distortion propensity, this was not specifically evaluated as part of this project.

Cooling time-temperature curves for a "fast" petroleum quench oil (HKM) and a conventional "slow" petroleum quench oil were obtained for comparison with the cooling behavior exhibited by the vegetable oils. As expected, the lower viscosity petroleum oil containing cooling rate accelerator additives exhibited the fastest cooling rate at the highest film boiling to nucleate boiling transition temperature of all of the oils evaluated. The conventional "slow" oil exhibited lower cooling rates at the lowest film boiling-nucleate boiling transition temperature, but, most importantly, it exhibited the longest duration of film boiling of the oils evaluated.

The HTCs were determined using a particle swarm computational method discussed herein. The results obtained essentially mirrored the conventional cooling time-temperature and cooling rate curves; however, the numerical data and graphical output provided a comparatively simpler and more relevant characterization overview than that provided by conventional cooling curve parameterization methods currently in use.

Finally, and perhaps most importantly, the heat transfer data obtained were used to predict the expected cross-sectional hardening properties that each oil would be expected to exhibit when used to quench a plain carbon steel. Based on these results, the HKM oil exhibited, by far, the best cross-sectional hardness. The two vegetable oils were noticeably poorer, with palm oil being less effective than canola oil. The poorer performance of palm oil was attributed to its longer film boiling transition time relative to canola oil. As expected, the conventional "slow" petroleum oil (H100) failed to exhibit any hardening at all. Through this example, the power of computational hardening analysis is shown. 


\section{Further Work}

The results reported here suggest that additional studies be performed on a broader range of vegetable oils to better understand their performance with respect to structural variations.

Another area of work suggested by these results is to obtain a better understanding of the variability of various sources of a vegetable oil and the expected impact on its quenching performance.

\section{ACKNOWLEDGMENTS}

The authors acknowledge the financial support of the Hungarian State and the European Union under the EFOP-3.6.1-16-2016-00010 project and the Hungarian-Japanese bilateral Scientific and Technological (TÉT_16-1-2016-0190) project. The authors also acknowledge Coordenação de Aperfeiçoamento de Pessoal de Nível Superior (CAPES) and Universidade de São Paulo (USP) for the financial support of this work. Without their support, this work would not have been possible.

\section{References}

[1] MacKenzie, D. S., "History of Quenching," Int. Heat. Treat. Surf. Eng., Vol 2, No. 2, 2013, pp. 68-73, https://doi.org/10.1179/174951508X358437

[2] Eamon, W., Science and Secrets of Nature - Book of Secrets in Medieval Europe and Early Modern Culture, Princeton University Press, Princeton, NJ, 1996, pp. 343-387.

[3] MacKenzie, D. S. and Graham, G., "Beer, Blood, and Urine - Mythological Quenchants of Ancient Blacksmiths," presented at the Conference Proceedings of $23^{\text {rd }}$ IFHTSE Congress, Savannah, GA, April 18-21, 2016, ASM International, Materials Park, OH, pp. 101-109.

[4] Simencio-Otero, R. L., Canale, L. C. F., and Totten, G. E., "Use of Vegetable Oils and Animal Oils as Steel Quenchants: A Historical Review-1850-2010," J. ASTM. Int., Vol. 9, No. 1, 2012, pp. 1-38, https://doi.org/10.1520/JAI103534

[5] Tagaya, M. and Tamura, I., "Studies on the Quenching Media (1st Report): An Analysis of Cooling Process During Quenching," Mem. Inst. Sci. Ind. Res. Osaka. Univ., Vol. 9, 1952, pp. 85-102.

[6] Tagaya, M. and Tamura, I., "No. 123-Studies on the Quenching Media (3rd Report): The Cooling Ability of Oils," Tech. Rep. Osaka. Univ., Vol. 4, 1954, pp. 305-319.

[7] Russell, T. F., Some Mathematical Considerations of the Heating and Cooling of Steel, First Report of the Alloy Steels Research Committee, Iron and Steel Institute, Washington, DC, 1936, pp. 149-187.

[8] Rose, A., "Das Abkühlungsvermögen von Stahl-Absscreckmilleln," Archiv für das Eisenhüttenwesen, Vol. 13, No. 8, 1940, pp. 345-354, https://doi.org/10.1002/srin. 194000899

[9] Otero, R. L. S., Canale, L. C. F., Schicchi, D. S., Agaliotis, E., Totten, G. E., and Sarmiento, G. S., "Epoxidized Soybean Oil: Evaluation of Oxidative Stabilization and Metal Quenching/Heat Transfer Performance," J. Mater. Eng. Perform., Vol. 22, No. 7, 2013, pp. 1937-1944, https://doi.org/10.1007/s11665-013-0546-7

[10] Kobasko, N. I., Batista, A. A., Canale, L. C., Totten, G. E., and Dobryvechir, V. V., "Cooling Capacity of Coconut Oil, Palm Oil, and a Commercial Petroleum Oil by Solving the Heat Conductivity Inverse Problem," Mater. Perform. Charact., Vol. 2, No. 1, 2013, pp. 319-338, https://doi.org/10.1520/MPC20120047

[11] Simencio Otero, R. L., "Calculation of Kobasko's Simplified Heat Transfer Coefficients from Cooling Curve Data Obtained with Small Probes," J. ASTM. Int., Vol. 9, No. 4, 2012, pp. 1-8, https://doi.org/10.1520/JAI104304 
[12] de Souza, E. C., Canale, L. C. F., Sánchez Sarmiento, G., Agaliotis, E., Carrara, J. C., Schicchi, D. S., and Totten, G. E., "Heat Transfer Properties of a Series of Oxidized and Unoxidized Vegetable Oils in Comparison with Petroleum Oil-Based Quenchants," J. Mater Eng. Perform., Vol. 22, No. 7, 2013, pp. 1871-1878, https://doi.org/10.1007/s11665-013-0514-2

[13] Jagannath, V. and Prabhu, K. N., "Severity of Quenching and Kinetics of Wetting of Nanofluids and Vegetable Oils," J. ASTM. Int., Vol. 6, No. 3, 2009, pp. 1-9, https:// doi.org/10.1520/JAI101800

[14] Ramesh, G. and Narayan Prabhu, K., "Wetting and Cooling Performance of Vegetable Oils during Quench Hardening," Heat Transfer Asian Res., Vol. 45, No. 4, 2016, pp. 342-357, https://onlinelibrary.wiley.com/doi/abs/10.1002/htj.21165

[15] Kobasko, N. and Liščić, B., "Liscic/Petrofer Probe to Investigate Real Industrial Hardening Processes and Some Fundamentals of Quenching Steel Parts in Liquid Media," EUREKA: Phys. Eng., Vol. 6, 2017, pp. 48-56, https://doi.org/10.21303/ 2461-4262.2017.00495

[16] Liščić, B., "Measurement and Recording of Quenching Intensity in Workshop Conditions Based on Temperature Gradients," Mater. Perform. Charact., Vol. 5, No. 1, 2016, pp. 209-226, https://doi.org/10.1520/MPC20160007

[17] Matijevic, B., Liščić, B., Totten, G. E., and Canale, L. C. F., "Comparative Measurement and Evaluation of the Quenching Intensity of Palm Oil, Canola Oil and a Conventional Petroleum Oil Quenchant Based on Temperature Gradient Measurements," Mater. Perform. Charact., Vol. 6, No. 5, 2017, pp. 757-776, https://doi.org/10.1520/MPC20170041

[18] Beck, J. V., Blackwell, B., and St. Clair, C. R., Jr., Inverse Heat Conduction, Wiley Interscience, New York, NY, 1985, 308p.

[19] Alifanov, O. M., Inverse Heat Transfer Problems, Springer Berlin/Heidelberg, Heidelberg, Germany, 1994, 348p.

[20] Özisik, M. N. and Orlande, H. R. B., Inverse Heat Transfer: Fundamentals and Applications, Taylor \& Francis, New York, NY, 2000, 352p.

[21] Verma, S. and Balaji, C., "Multi-Parameter Estimation in Combined Conduction Radiation from a Plane Parallel Participating Medium Using Genetic Algorithms," Int. J. Heat Mass. Trans., Vol. 50, Nos. 9-10, 2007, pp. 1706-1714, https://doi.org/10. 1016/j.ijheatmasstransfer.2006.10.045

[22] Kim, K. W. and Baek, S. W., "Inverse Surface Radiation Analysis in an Axisymmetric Cylindrical Enclosure Using a Hybrid Genetic Algorithm," Numer. Heat Trans. Part A: Appl., Vol. 46, No. 4, 2004, pp. 367-381, https://doi.org/10.1080/10407780490478533

[23] Felde, I., "Prediction of Thermal Boundary Conditions Obtained during Immersion Quenching," presented at the 20th IFHTSE- International Federation for Heat Treatment and Surface Engineering, Beijing, China, October 23-25, 2012, Chinese Heat Treatment Society, Beijing, China, pp. 837-840.

[24] Felde, I., Baán, M. K., and Shi, W., "Characterization of Heat Transfer during Quenching by Using Optimization Techniques" presented at the Second International Conference on Energy and the Future of Heat Treatment and Surface Engineering, Beijing, China, October 11-13, 2014, Chinese Heat Treatment Society, Beijing, China.

[25] Felde, I., Szénási, S., Kenéz, A., Wei, S., and Colas, R., "Determination of Complex Thermal Boundary Conditions Using a Particle Swarm Optimization Method," presented at the Fifth International Conference on Distortion Engineering, Bremen, Germany, 23-25 September, 2015, 227-236.

[26] Felde, I., Szénási, S., Fried, Z., and Wei, S., "Investigation of Parallelized PSO Algorithm Applied to Estimate Complesx HTC," presented at the Fifth Asian Conference on Heat Treatment and Surface Engineering, Beijing, China, 12-14 November, 2016, Chinese Heat Treatment Society, Beijing, China, pp. 263-269.

[27] ASTM D445-17a, Standard Test Method for Kinematic Viscosity of Transparent and Opaque Liquids (and Calculation of Dynamic Viscosity), ASTM International, West Conshohocken, PA, 2017, www.astm.org 
[28] ASTM D2270-10, Standard Practice for Calculating Viscosity Index from Kinematic Viscosity at $40^{\circ} \mathrm{C}$ and $100^{\circ} \mathrm{C}$, ASTM International, West Conshohocken, PA, 2016, www.astm.org

[29] ASTM D6200-01, Standard Test Method for Determination of Cooling Characteristics of Quench Oils by Cooling Curve Analysis, ASTM International, West Conshohocken, PA, 2017, www.astm.org

[30] Srinivasan, V., Moon, K.-M., Greif, D., Wang, D. M., and Kim, M.-H., "Numerical Simulation of Immersion Quench Cooling Process Using an Eulerian Multi-Fluid Approach," Appl. Therm. Eng., Vol. 30, No. 5, 2010, pp. 499-509, https://doi.org/ 10.1016/j.applthermaleng.2009.10.012

[31] Ko, D.-H., Ko, D.-C., Lim, H.-J., and Kim, B.-M., “Application of QFA Coupled with CFD Analysis to Predict the Hardness of T6 Heat Treated A16061 Cylinder," J. Mech. Sci. Technol., Vol. 27, No. 9, 2013, pp. 2839-2844, https://doi.org/10.1007/s12206013-0732-4

[32] Banka, A. L., Ferguson, B. L., and MacKenzie, D. S., "Evaluation of Flow Fields and Orientation Effects Around Ring Geometries during Quenching," J. Mater. Eng. Perform., Vol. 22, No. 7, 2013, pp. 1816-1825, https://doi.org/10.1007/s11665013-0509-z

[33] Le Masson, P., Loulou, T., and Artioukhine, E., "Estimations of a 2D Convection Heat Transfer Coefficient during a Metallurgical 'Jominy End-Quench' Test: Comparison between Two Methods and Experimental Validation," Inverse Prob. Sci. Eng., Vol. 12, No. 6, 2004, pp. 595-617, https://doi.org/10.1080/10682760310001598643

[34] Ren, T., Modest, M. F., Fateev, A., and Clausen, S., “An Inverse Radiation Model for Optical Determination of Temperature and Species Concentration: Development and Validation," J. Quant. Spectrosc. Radiat. Transfer, Vol. 151, 2015, pp. 198-209, https://doi.org/10.1016/j.jqsrt.2014.10.005

[35] Storn, R. and Price, K., "Differential Evolution-A Simple and Efficient Heuristic for Global Optimization over Continuous Spaces," J. Global Optim., Vol. 11, No. 4, 1997, pp. 341-359, https://doi.org/10.1023/A:100820282

[36] Chopade, R. P., Mohan, V., Mayank, R., Uppaluri, R. V. S., and Mishra, S. C., "Simultaneous Retrieval of Parameters in a Transient Conduction-Radiation Problem Using a Differential Evolution Algorithm," Numer. Heat Transfer A: Appl., Vol. 63, No. 5, 2013, pp. 373-395, https://doi.org/10.1080/10407782.2013. 733179

[37] Li, H. Y. and Yang, C. Y., "A Genetic Algorithm for Inverse Radiation Problems," Int. J. Heat Mass Transfer., Vol. 40, No. 7, 1997, pp. 1545-1549, https://doi.org/10. 1016/S0017-9310(96)00233-5

[38] Das, R., Mishra, S. C., and Uppaluri, R., "Inverse Analysis Applied to Retrieval of Parameters and Reconstruction of Temperature Field in a Transient ConductionRadiation Heat Transfer Problem Involving Mixed Boundary Conditions," Int. Commun. Heat Mass Transfer., Vol. 37, No. 1, 2010, pp. 52-57, https://doi.org/ 10.1016/j.icheatmasstransfer.2009.07.016

[39] Kennedy, J. and Eberhart, R. C., "Particle Swarm Optimization," presented at the MHS'95. Sixth International Symposium on Micro Machine and Human Science, Nagoya, Japan, 4-6 October, 1995, Institute of Electrical and Electronics Engineers, Piscataway, NJ, pp. 1942-1948, https://doi.org/10.1109/MHS.1995.494249

[40] Yuan, Y., Yi, H.-L., Shuai, Y., Wang, F.-Q., and Tan, H.-P., "Inverse Problem for Particle Size Distributions of Atmospheric Aerosols Using Stochastic Particle Swarm Optimization," J. Quant. Spectrosc. Radiat. Transfer, Vol. 111, No. 14, 2010, pp. 2106-2114, https://doi.org/10.1016/j.jqsrt.2010.03.019

[41] Qi, H., Ruan, L. M., Zhang, H. C., Wang, Y. M., and Tan, H. P., "Inverse Radiation Analysis of a One-Dimensional Participating Slab by Stochastic Particle Swarm Optimizer Algorithm," Int. J. Therm. Sci., Vol. 46, No. 7, 2007, pp. 649-661, https://doi.org/10.1016/j.ijthermalsci.2006.10.002

[42] Clerc, M., "The Swarm and the Queen: Towards a Deterministic and Adaptive Particle Swarm Optimization," presented at the Congress on Evolutionary 
Computation-CEC 1999, Washington, DC, 1999, Institute of Electrical and Electronics Engineers, Piscataway, NJ, pp. 1951-1957, https://doi.org/10.1109/ CEC.1999.785513

[43] Esteban, B., Riba, J.-R., Baquero, G., Rius, A., and Puig, R., "Temperature Dependence of Density and Viscosity of Vegetable Oils," Biomass Bioenergy, Vol. 42, 2012, pp. 164-171, https://doi.org/10.1016/j.biombioe.2012.03.007

[44] Fasina, O. O. and Colley, Z., "Viscosity and Specific Heat of Vegetable Oils as a Function of Temperature $35^{\circ} \mathrm{C}$ to $180^{\circ} \mathrm{C}$," Int. J. Food Prop., Vol. 11, No. 4, 2008, pp. 738-746, https://doi.org/10.1080/10942910701586273

[45] Felde, I. and Réti, T., "Evaluation of Hardening Performance of Cooling Media by Using Inverse Heat Conduction Methods and Property Prediction," Strojniski Vestnik- J. Mech. Eng., Vol. 56, No. 2, 2010, pp. 77-83.

[46] Reti, T., Fried, Z., and Felde, I., "Computer Simulation of Steel Quenching Process Using a Multi-Phase Transformation Model," Comput. Mater. Sci., Vol. 22, Nos. 3-4, 2001, pp. 261-278, https://doi.org/10.1016/S0927-0256(01)00240-3

[47] Felde, I. and Réti, T., "Evaluation of Cooling Characteristics of Quenchants by Using Inverse Heat Conduction Methods and Property Prediction," Mater. Sci. Forum., Vol. 659, 2010, pp. 153-158, https://doi.org/10.4028/www.scientific.net/MSF.659.153 